\title{
Development and Validation of an Instrument for Assessing Users' Views about the Usability of Digital Libraries
}

\author{
Alex Koohang \\ University of Wisconsin - Milwaukee, USA
}

koohang@uwm.edu

\begin{abstract}
This paper attempted to develop and validate an instrument that measures users' views about the usability of digital libraries. Users' views toward the usability of digital libraries may serve as the major conduit to user acceptance and satisfaction, thus promoting positive learning experiences. The instrument, digital library usability, consisted of 12 items that described usability properties of digital libraries. The content validity of the instrument was determined by a panel of experts. The instrument was administered to 293 subjects. The construct validity was determined by conducting a set of statistical procedures, including a principal component analysis. The results revealed a single component solution that assessed one particular trait. All items of the instrument achieved high loading values indicating that each item contributed to the assessment of the single component that accounted for a high variation among the items. The internal consistency (Cronbach alpha) was .96 . These results suggest that the digital library usability instrument is a valid and reliable instrument that can measure users' views about the usability of digital libraries. This instrument can be the basis for future research regarding users' views toward the usability of digital libraries.
\end{abstract}

Keywords: Usability, Usability Attributes, Usability Properties, Digital Library, Electronic Library, Virtual Library, Users' views, Instrument Validation, Content Validity, Construct Validity, Reliability

\section{Introduction}

A digital library is a blend of "(1) a service; (2) an architecture; (3) a set of information resources, databases of text, numbers, graphics, sound and video etc.; and (4) a set of tools and capabilities to locate, retrieve and utilize the information resources available" Borgman (2000, p. 41). Watstein, Calarco, \& Ghaphery, (1999) reported that terms such as virtual libraries, on-line libraries, and electronic libraries are used simultaneously and/or interchangeability with the term digital libraries.

The Association of Research Libraries (ARL) has suggested a definition for digital libraries that was advanced by Drabenstott (1994). This definition consists of elements that are common to

Material published as part of this journal, either on-line or in print, is copyrighted by Informing Science. Permission to make digital or paper copy of part or all of these works for personal or classroom use is granted without fee provided that the copies are not made or distributed for profit or commercial advantage AND that copies 1) bear this notice in full and 2) give the full citation on the first page. It is permissible to abstract these works so long as credit is given. To copy in all other cases or to republish or to post on a server or to redistribute to lists requires specific permission from the publisher at Publisher@InformingScience.org terms used to explain digital libraries. These elements are:

- The digital library is not a single entity; 
- The digital library requires technology to link the resources of many;

- The linkages between the many digital libraries and information services are transparent to the end users;

- Universal access to digital libraries and information services is a goal; and

- Digital library collections are not limited to document surrogates: they extend to digital artifacts that cannot be represented or distributed in printed formats.

Digital libraries are increasingly becoming a part of the digital learning communities, in particular, distance education. Roes (2001) stated that digital libraries are natural complements to electronic learning settings. Digital libraries have many benefits such as bringing information to users; providing enhanced searching, sharing; collaboration, and use of information; and lessening the digital divide (Arms 2000).

McCray \& Gallagher (2001) stated that designing a usable system is one of the major principles in developing digital libraries. The authors believe that characteristics such as accessibility, simplicity, user control, and clear navigation should be incorporated into the design for usability of digital libraries.

Usability is generally characterized as the determining aspect of a product or system's capability to satisfy the needs and specifications of users. Usability is the extent of how users easily and effectively use a product or system. It plays a vital role in user acceptance of a product or system (Dumas \& Redish, 1993; Guillemette, 1989; Holms, 2002; Nielsen 1993; Nielsen, 2000; Rosenbaum, 1989; Rubin, 1994; Shackel 1991).

A digital library is a system that must be usable. Much of the literature in the area of usability of digital libraries has been on testing and evaluation (Dickstein \& Mills, 2000; McGillis \& Toms, 2001; McMullen, 2001; Walbridge, 2000). A critical, yet largely unexamined facet of usability of digital libraries is the users' views of the usability of digital libraries. Research has acknowledged that users' views play a vital role in determining the usability of digital libraries (Blanford, Stelmaszewska, \& Byyan-Kinns, 2001; Covi and Kling 1997). One's behavior based on his or her views about the usability of digital libraries may play an important role in the success of learning in general. Therefore, this study attempted to develop and validate an instrument that measures users' views about the usability of digital libraries. Users' views may serve as the major intermediary to user acceptance and satisfaction, thus promoting positive learning experience.

\section{Development of the Instrument: Content Validity}

The literature has documented many usability attributes that are the end result of a usable product or system. In general the following usability attributes are reported in the literature: effectiveness, learnability, flexibility, and attitude (Shackle, 1991); learnability, efficiency, memorability, errors, and satisfaction (Nielsen, 1993); effectiveness, efficiency, and satisfaction (ISO 9241-11, 1998); and understandability, learnability, operability, and attractiveness (ISO 9126-1, 1991).

Each usability attribute may be linked to one or more properties that describe a usable system. The properties are elements such as simplicity, recognition, navigability, etc. that are designed into a product or system to make it usable. Many usability properties are reported in the literature (Dumas \& Redish, 1993; Guillemette, 1989; Holms, 2002; Nielsen 1993; Nielsen, 2000;

Rosenbaum, 1989; Rubin, 1994; Shackel 1991). For example, simplicity is a usability property. If this property is designed into a product or system then that product or system can be considered usable. The presence of this property may influence one or more usability attributes such as user satisfaction, learnability, efficiency, and positive attitude.

Similar to any product or system, a digital library must possess usability properties. In other 
words, in designing digital libraries for usability, appropriate usability properties must be used. For the purpose of this study, a set of usability properties were chosen from the literature that would describe usability of digital libraries. These usability properties for digital libraries were taken to the next step of instrument development and validation - content validity.

The content validity of the instrument was determined by a panel of experts consisting of five university professors whose expertise included the fields of information technology, information systems, and information science. The items of the instrument were usability properties that were chosen from an original pool of 15 items. These items described usability of digital libraries. Several items were modified from their original form to maximize the accuracy and clarity of the items. Three items were eliminated because the panel of experts had determined that they were duplicates of other items. It was the consensus of the panel of experts that the individual items chosen assessed the intended concepts, and that the instrument as a whole was a valid measure of usability of digital libraries. The final instrument consisted of 12 items that described the usability of digital libraries. These items are described below:

- Simplicity: A digital library must be simple to use. Simplicity may be linked to usability attributes such as learnability, efficiency, satisfaction, and attitude.

- Comfort: Users must feel comfortable using a digital library. The usability attributes linked to comfort may include learnability, efficiency, satisfaction, and attitude.

- User friendliness: A digital library must be user-friendly. The attributes connected to this property may include attractiveness, learnability, efficiency, satisfaction, and attitude.

- Control: Users must be in control of using a digital library. The usability attributes that affect this property may include operability, learnability, effectiveness, efficiency, satisfaction, and attitude.

- Readability: Accessed information by users from a digital library must be uncluttered and readable. The usability attributes linked to readability may include understandability, attractiveness, learnability, effectiveness, efficiency, satisfaction, and attitude.

- Information Adequacy/Task Match: The accessed information from a digital library must be adequate. In other words, a digital library is much more usable if there is adequate information - no more, no less. The usability attributes connected to this property may include effectiveness, efficiency, satisfaction, and attitude.

- Navigability: Users must be able to navigate with ease, freely, and without problem throughout a digital library. The usability attributes linked to this property may include operability, learnability, effectiveness, efficiency, satisfaction, and attitude.

- Recognition: Users must be able to quickly understand the features and functions available in a digital library. The attributes linked to this property may include memorability, error, learnability, efficiency, satisfaction, and attitude.

- Access time: The information queried from a digital library must be loaded in a reasonable time. The attributes linked to this property may include flexibility, effectiveness, efficiency, satisfaction, and attitude.

- Relevancy: The information accessed from a digital library must be relevant. The attributes linked to this property may include effectiveness, efficiency, satisfaction, and attitude. 
- Consistency: The consistency of terms, words, and actions must be present throughout a digital library. The attributes linked to this property may include memorability, learnability, efficiency, satisfaction, and attitude.

- Visual Presentation: Appropriate visual presentation such as text boldfacing, underlining, and italicizing must be present in a digital library. The attributes linked to this property may include effectiveness, efficiency, attractiveness, satisfaction, and attitude.

The instrument used the Likert technique. A five-point scale was developed with five response choices. They were: strongly agree $=5$, agree $=4$, neither agree nor disagree $=3$, disagree $=2$, and strongly disagree $=1$. Listed below are the instrument items:

1. Simplicity: The digital library was simple to use.

2. Comfort: I felt at ease using the digital library.

3. User friendliness: The digital library was user-friendly.

4. Control: I felt in control of using the digital library.

5. Readability: The information I accessed from the digital library was uncluttered and readable.

6. Adequacy/Task Match: The accessed information from the digital library was adequate.

7. Navigability: I was able to move around throughout the digital library with ease.

8. Recognition: I quickly understood the features and functions available in the digital library.

9. Access time: The information I asked for from the digital library loaded in a reasonable time.

10. Relevancy: The information I got from the digital library was relevant.

11. Consistency: The consistency of terms, words, and actions used throughout the digital library was evident.

12. Visual Presentation: Text boldfacing, italicizing, and underlining were present in the digital library to grab my attention.

This instrument uses the Human Computer Interaction (HCI) participative evaluation method using a questionnaire. This method entails collecting data about usability of digital libraries directly from users' subjective point of views. This method has the ability to acquire all characteristics related to "users' needs, desires, thought processes, and experiences that are difficult to obtain otherwise" (Hilbert \& Redmiles, 2000, p. 389).

\section{Method}

\section{Subjects}

A total of 293 students who were enrolled in an undergraduate hybrid program in management completed the instrument. The subjects were males and females from a multi-campus university in the Midwest, USA. They were enrolled in courses such as supervision, communication, research design, organizational behavior, and human resources. All subjects had completed at least several mini-research paper/essay assignments that required the extensive use of the university's digital library.

The terms electronic library and digital library were used interchangeably by subjects. The digital library used by subjects of this study is a virtual library that is a subset of the actual physical library. It is accessed via the Internet using computer networks. In particular, this digital library included a large number of databases that contain digital full-text of scholarly journals, substantive news periodicals, general interest periodicals, and popular periodicals. Other features of the digital library included on-line catalogs for finding books and periodical list, a comprehensive on- 
line tutorial, and asynchronous support by e-mail. All students were required to attend a two-hour library orientation session in the beginning of their program.

The subjects were told that their participation in completing the instrument were entirely voluntarily. All participants were 18 years or older. They were told not to put their names on the instrument. The subjects were guaranteed anonymity with regard to the publication of the results.

\section{Data analyses}

The following statistical analyses were conducted using SPSS:

1. Kaiser-Meyer-Olkin Measure of Sampling Adequacy was conducted to ensure that there was adequate and high variability in the collected data.

2. Bartlett Test of Sphericity was conducted to ensure that the items of the instrument were sufficiently correlated.

3. Principal component analysis with Varimax rotation was conducted on the collected data. This method was used to determine the number of components to retain.

4. Reliability test (Cronbach alpha) was conducted to find internal consistency among the items.

\section{Results}

\section{Construct Validity}

The data were inspected with regard to their appropriateness for component analysis through the Kaiser-Meyer-Olkin Measure of Sampling Adequacy and the Bartlett Test of Sphericity. The Kaiser-Meyer-Olkin Measure for the date was .885, which suggested that there was sufficient and high variability in the data to conduct component analysis. The results of Bartlett Test of Sphericity (Approximate Chi-Square $=4828.65, \mathrm{df}=66$, Sig. $=.000$ ) suggested that the items were sufficiently correlated to conduct component analysis. (See Table 1)

Table 1: KMO and Bartlett's Test

\begin{tabular}{|r|r|r|}
\hline Kaiser-Meyer-Olkin Measure of Sampling Adequacy & .888 \\
\hline Bartlett's Test of Sphericity & Approx. Chi-Square & 4701.567 \\
\hline & df & 66 \\
\hline & Sig. & .000 \\
\hline
\end{tabular}

The principal component analysis extracted one single solution with eigenvalue greater than 1 . All items were retained and achieved loading values of greater than .64, which suggested that each item contributed to the assessment of the single component solution (See Tables $2 \& 3$ ). The single component model accounted for $73.04 \%$ of the variation among the items. No rotation was attempted by SPSS after finding a single component solution. 
Table 2: Communalities

\begin{tabular}{|r|r|r|}
\hline & Initial & Extraction \\
\hline Simplicity & 1.000 & .715 \\
\hline Comfort & 1.000 & .723 \\
\hline User friendliness & 1.000 & .707 \\
\hline Control & 1.000 & .760 \\
\hline Readability & 1.000 & .783 \\
\hline Information Adequacy/Task Match & 1.000 & .649 \\
\hline Navigability & 1.000 & .765 \\
\hline Recognition & 1.000 & .744 \\
\hline Access time & 1.000 & .764 \\
\hline Relevancy & 1.000 & .692 \\
\hline Consistency & 1.000 & .732 \\
\hline Visual Presentation & 1.000 & .729 \\
\hline
\end{tabular}

Table 3: Principal Component Analysis (Component Matrix)

\begin{tabular}{|r|r|}
\hline & Component 1 \\
\hline Simplicity & .846 \\
\hline Comfort & .851 \\
\hline User friendliness & .841 \\
\hline Control & .872 \\
\hline Readability & .885 \\
\hline Information Adequacy/Task Match & .806 \\
\hline Navigability & .874 \\
\hline Recognition & .863 \\
\hline Access time & .874 \\
\hline Relevancy & .832 \\
\hline Consistency & .856 \\
\hline Visual Presentation & .854 \\
\hline
\end{tabular}

Table 4: Descriptive Statistics

\begin{tabular}{|r|r|r|r|r|r|}
\hline & $\mathrm{N}$ & Min & Max & Mean & SD \\
\hline Simplicity & 293 & 1.00 & 5.00 & 3.8976 & .95968 \\
\hline Comfort & 293 & 1.00 & 5.00 & 3.9010 & .97596 \\
\hline User friendliness & 293 & 1.00 & 5.00 & 3.9556 & .94075 \\
\hline Control & 293 & 1.00 & 5.00 & 3.9352 & .92856 \\
\hline Readability & 293 & 1.00 & 5.00 & 3.6826 & 1.00594 \\
\hline Information Adequacy/Task Match & 293 & 1.00 & 5.00 & 3.7543 & 1.03419 \\
\hline Navigability & 293 & 1.00 & 5.00 & 3.8020 & 1.03784 \\
\hline Recognition & 293 & 1.00 & 5.00 & 3.7884 & 1.04173 \\
\hline Access time & 293 & 1.00 & 5.00 & 3.7747 & 1.01552 \\
\hline Relevancy & 293 & 1.00 & 5.00 & 3.7440 & 1.05630 \\
\hline Consistency & 293 & 1.00 & 5.00 & 3.9386 & .91579 \\
\hline Visual Presentation & 293 & 1.00 & 5.00 & 3.8191 & 1.00242 \\
\hline
\end{tabular}




\section{Reliability}

A reliability coefficient (Cronbach alpha) was calculated using the internal consistency method. The calculated coefficient alpha reliability from the results was .96, which suggests that this instrument is highly suitable to measure users' views about the usability of digital libraries. The results of correlation matrix, means, and standard deviations are shown in Tables $4 \& 5$.

Table 5: Correlation Matrix

\begin{tabular}{|lllllllllllll|}
\hline \multicolumn{2}{|c}{ V1 } & V2 & V3 & V4 & V5 & V6 & V7 & V8 & V9 & V10 & V11 & V12 \\
V1 & 1.00 & & & & & & & & & & & \\
V2 & 0.87 & 1.00 & & & & & & & & & & \\
V3 & 0.81 & 0.83 & 1.00 & & & & & & & & & \\
V4 & 0.70 & 0.69 & 0.71 & 1.00 & & & & & & & & \\
V5 & 0.69 & 0.70 & 0.72 & 0.78 & 1.00 & & & & & & & \\
V6 & 0.59 & 0.59 & 0.64 & 0.66 & 0.74 & 1.00 & & & & & & \\
V7 & 0.64 & 0.65 & 0.62 & 0.70 & 0.75 & 0.73 & 1.00 & & & & & \\
V8 & 0.68 & 0.67 & 0.65 & 0.68 & 0.73 & 0.73 & 0.80 & 1.00 & & & & \\
V9 & 0.72 & 0.74 & 0.69 & 0.70 & 0.75 & 0.63 & 0.74 & 0.74 & 1.00 & & & \\
V10 & 0.68 & 0.69 & 0.68 & 0.66 & 0.70 & 0.64 & 0.69 & 0.69 & 0.84 & 1.00 & & \\
V11 & 0.68 & 0.68 & 0.69 & 0.97 & 0.77 & 0.63 & 0.68 & 0.68 & 0.68 & 0.63 & 1.00 & \\
V12 & 0.62 & 0.63 & 0.59 & 0.68 & 0.73 & 0.71 & 0.97 & 0.78 & 0.71 & 0.65 & 0.69 & 1.00 \\
& & & & & & & & & & & & \\
\hline
\end{tabular}

$V 1=$ Simplicity, $V 2=$ Comfort, $V 3=$ User friendliness, $V 4=$ Control, $V 5=$ Readability, V6 = Information Adequacy/Task Match, V7 = Navigability, V8 = Recognition, V9 = Access time, $V 10=$ Relevancy, $V 11=$ Consistency, $V 12=$ Visual Presentation

\section{Conclusion}

The literature has documented that usability of a system or product contributes to attributes such as users' effectiveness, learnability, flexibility, attitude, efficiency, memorability, satisfaction, and understandability, thus creating a positive learning environment for users to accomplish tasks that meet their goals. A usable system contains usability properties that lead to usability attributes.

Digital libraries are increasingly becoming a part of the digital learning settings. For this reason, the usability of digital libraries becomes an important issue for both users and designers. Unquestionably, a digital library must possess usability properties which results in attributes that affect users' positive and successful learning experience.

One's positive views toward the usability of digital libraries may play an important role in his or her successful accomplishment of tasks, thus ensuring rewarding learning experience. This study attempted to develop and validate an instrument that measures users' views toward the usability of digital libraries. A set of usability properties that described usability of digital libraries was selected for the instrument. Each property was formed into an item/statement. A panel of experts concluded that the items of the instrument were suitable to measure users' views toward the usability of digital libraries. In other words, the instrument as a whole was a valid measure of usability of digital libraries.

Initial analyses of the collected data for the instrument suggested that the items of the instrument were sufficiently correlated and that there was adequate and high variability in the collected data to conduct principal component analysis. The results of principal component analysis indicated that the digital library usability instrument measured one particular trait. The analysis revealed a single component solution. All items of the instrument achieved high loading values indicating that each item contributed to the assessment of the single component that accounted for a high variation among the items. The internal consistency (reliability estimate) for the instrument was 
.96 indicating a very high reliability. The Cronbach alpha showed a homogeneous set of items that measure users' views toward the usability of digital libraries.

Currently, the multitudes of commercial digital libraries contain many databases that do not follow universal techniques for system usability. Such techniques are perhaps being developed, however; the digital libraries lack the same standardization for system usability. Measuring users' views about the usability of digital libraries may assist designers of digital libraries to be sensitive to the needs and specifications of users regarding the usability of digital libraries. It may also assist the designers of digital libraries in initiating usability standardization within and across all digital libraries.

The results of this study were indicative of a valid and reliable instrument that can measure users' views toward the usability of digital libraries. This instrument represents an initial step toward the establishment of a measurement technique for users' views toward the usability of digital libraries. However, efforts must be made to further improve this instrument by possibly expanding emerging usability properties that might further describe the usability of digital libraries. Furthermore, this instrument may be used as the foundation for future research regarding users' views toward the usability of digital libraries.

\section{References}

Arms, E. (2000). Digital libraries. Cambridge, MA: MIT Press.

Borgman, C. (2000). From Gutenberg to the global information infrastructure: Access to information in the networked world. Cambridge, MA: MIT Press

Blandford, A. E., Harrison, M. D. \& Barnard, P. J. (1995). Using interaction framework to guide the design of interactive systems. International Journal of Human-Computer Studies, 43, 101-130.

Covi, L. \& Kling, R. (1997). Organisational dimensions of effective digital library use: Closed rational and open natural systems model. In S. Kiesler, Culture of the Internet (pp. 343-360). New Jersey: Lawrence Erlbaum.

Dickstein, R. \& Mills, R. (2000). Usability testing at the University of Arizona Library: How to let the users in on the design. Information Technology \& Libraries, 19 (3), 144-151.

Drabenstott, Karen M. (1994). Analytical review of the library of the future. Washington, DC: Council Library Resources.

Dumas, J. \& Redish, J. (1993). A practical guide to usability testing. Norwood, New Jersey: Ablex.

Guillemette, R. A. (1989). Usability in computer documentation design: Conceptual and methodological considerations. IEEE Transactions on Professional Communication, 32, 217-28.

Hilbert, D. \& Redmiles, D. (2000). Extracting usability information from user interface events. ACM Computing Surveys, 32 (4).

Holms, M. (2002). Web usability \& navigation. New York: McGraw-Hill

ISO 9241-11 (1998). Ergonomic requirements for office work with visual display terminals (VDT)s - Part 11 Guidance on usability.

ISO 9126 -1 (1991). Software product evaluation - Quality characteristics and guidelines for their use.

McCray A. \& Gallagher, M. (2001). Principles for Digital Library Development. Communications of the ACM, 44(5), 49-54.

McGill, L. \& Toms, L. (2001). Usability of the academic library web site: Implications for design. College \& Research Libraries, 62 (4), 355-367.

McMullen, S. (2001). Usability testing in a library web site redesign project. Reference Service Review, 29 (1), 7-22. 
Nielsen, J., (1993). Usability engineering. San Diego, CA: Academic Press.

Nielsen, J. (2000). Designing Web usability: The practice of simplicity. Indianapolis: New Riders.

Robins, S. (2001). Organizational behavior (9th ed.). New Jersey: Prentice-Hall.

Roes, H. (2001). Digital libraries and education: Trends and opportunities. D-Lib Magazine, 7 (7/8).

Rosenbaum, S. (1989). Usability evaluations vs. usability testing: When and Why? IEEE Transactions on Professional Communication, 32, 210-16.

Rubin, J. (1994). Handbook of usability testing. New York: John Wiley.

Shackel, B., (1991). Usability - context, framework, design and evaluation. In B. Shackel, \& S. Richardson (Eds.). Human Factors for Informatics Usability (pp. 21-28). Cambridge: Cambridge University Press.

Walbridge, S. (2000). Usability testing and libraries: The WSU experience. ALKI, 16 (3), 23-4.

Watstein, S., Calarco, P. \& Ghaphery, J. (1999). Digital library: Keywords. Reference Services Review, 27 (4), 344-352.

\section{Biography}

Dr. Alex Koohang is an associate professor and director of undergraduate program in the School of Information Studies at University of Wisconsin - Milwaukee, USA. Dr. Koohang has designed, developed, and implemented various traditional, non-traditional, hybrid, and on-line courses/programs. He has been involved in the development of on-line education, having initiated and administered some of the earliest asynchronous learning networks. His current research interests are in the areas of distance/e-learning, system usability, learning objects and reusability. 